\title{
Развитие отечественной электроники - не прихоть, а острая необходимость
}

\author{
Рассказывает директор Департамента радиоэлектронной \\ промышленности Минпромторга России В.В.Шпак
}

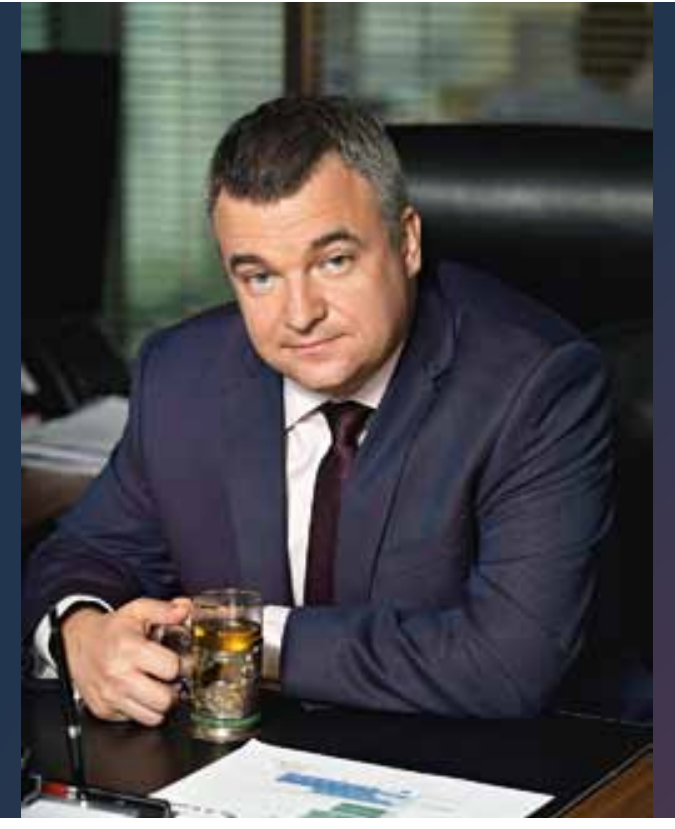
В условиях перехода к цифровой модели экономических и общественных отношений электроника уже не может рассматриваться просто как одна из отраслей: ей уготована особая роль в определении настоящего и формировании будущего человечества, а развитие электронной отрасли становится государственной задачей. О том, почему так важно, чтобы в нашей стране была собственная электроника, что для этого требуется, какие шаги планируются и какие меры уже приняты для достижения этой цели, нам рассказал директор Департамента радиоэлектронной промышленности Министерства промышленности и торговли Российской Федерации, к. э. н. Василий Викторович Шпак.

Василий Викторович, разрешите поздравить вас с назначением на должность директора Департамента радиоэлектронной промышленности. Какие первоочередные задачи стоят сейчас перед вами и департаментом в целом?

В контексте последних решений руководства страны, поручений Президента РФ В.В.Путина и Правительства Российской Федерации особое внимание в деятельности министерства уделяется развитию микроэлектроники

Причина приоритетности этого направления совершенно ясна: наш мир движется в направлении перехода на цифровую модель экономических и общественных отношений. Электроника в целом и микроэлектроника в частности - это "сосуды» цифровой экономики и цифрового общества, по которым течет их “кровь»-информация. Количество информации вырастает кратно с каждым годом. Огромными темпами растет и ее значимость для людей. Для подрастающего поколения виртуальный мир, например социальные сети, подчас обладает не меньшей важностью, чем мир реальный. Дети начинают играть в игры на планшетах раньше, чем учатся читать. Всего несколько лет назад такое было невозможно себе представить. Подумайте только: первый іPhone появился в 2007 году, а сотовая связь стала широко доступной всего около 20 лет назад. И как вы себя чувствуете сегодня, если забудете свой смартфон дома?

Конечно, в масштабах планеты этот прогресс идет неоднородно. Сейчас часто можно услышать слова о том, что мир переходит на шестой технологический уклад, однако так говорить про весь мир еще рано. Только на рубеже 2018-2019 годов появились данные исследований, указывающих на то, что количество пользователей Интернета преодолело порог 50\% от населения Земли. По различным данным, широкополосный доступ к сети Интернет на сегодняшний день на нашей планете имеют порядка 2-2,5 млрд человек. Поэтому до того, как весь мир вступит в цифровую эру, еще есть некоторый временной зазор. Но учитывая темпы прогресса, этот зазор не так уж и велик. И как только это случится, мы увидим кардинальные перемены в обществе, в экономике, в политике.

В связи с этим, умение взаимодействовать с информацией таким образом, чтобы она делала жизнь людей лучше, начинает играть определяющую роль не только в построении экономики будущего, но и в перспективах существования цивилизации в целом, а наличие собственных “информационных сосудов" в организме государства становится залогом его суверенитета и национальной 
безопасности. Если у него не будет своей электроники, в ближайшем будущем оно суверенным государством де-факто быть не сможет.

Понимание этого правительствами развитых стран приводит к регионализации, к формированию технологических зон, вбирающих в себя, насколько возможно, все технологии для создания электроники. Такая технологическая зона должна быть создана и в России. Задача развития собственной электроники - и микроэлектроники в частности - это не просто красивые слова о поддержке отечественного производителя, а острая, насущная и осознанная необходимость, и руководство нашей страны это отчетливо понимает.

Из сказанного вами можно сделать вывод, что, хотя в качестве приоритетного направления обозначена микроэлектроника, за этим стоят задачи, выходящие далеко за ее пределы и охватывающие все аспекты развития электронной аппаратуры.

Не только аппаратуры, но законченных платформ и услуг. Дело в том, что в современных условиях микроэлектроника не может быть изолированным объектом развития. Ни микроэлектроника, ни приборы, ни аппаратура сами по себе уже не продаются - продаются услуги. Это можно наблюдать и на потребительском рынке, и на рынке государственного заказа. Приобретая мобильный телефон, мы не задумываемся, из чего он состоит, пользуемся его программным обеспечением (ПО), устанавливаем новые приложения с помощью сервисов, уже имеющихся в телефоне, и т. п. Государственные и муниципальные учреждения так же не закупают отдельно ПО и компьютеры, а тем более комплектующие. Они приобретают готовые услуги у оператора или интегратора, что включает в том числе и аппаратное обеспечение. Где приобретает компьютеры интегратор - это уже другой вопрос, и здесь, на самом деле, есть над чем работать, потому что, хотя большинство операторов и интеграторов - отечественные компании, оборудование, на котором основаны их услуги, нередко импортное.

Таким образом, решающее значение для того, чтобы образовалась воронка продаж для микроэлектроники, имеет рынок услуг на основе программно-аппаратных комплексов - платформ, которые и формируют виртуальную среду, являющуюся основой цифрового будущего. Поэтому, чтобы развивать микроэлектронику, необходимо понимать рынок и обеспечивать развитие во всех звеньях цепочки: от приборов и аппаратуры до программного обеспечения и готовых платформ. И, что немаловажно, нужно обеспечить качественное предоставление услуг на этих платформах, гарантийную и постгарантийную поддержку, сопровождение в течение всего жизненного цикла, с чем у нас часто бывают проблемы.
Это очень масштабная задача. Есть ли уверенность в реалистичности ее решения?

Конечно, "по щелчку" это сделать невозможно. Здесь нужен системный подход. Но о том, что это вполне реально, говорит успешный опыт тех масштабных проектов, которые наша страна реализовала в прошлом.

я имею в виду прежде всего советские космический и атомный проекты, где благодаря большим совместным усилиям и централизации ресурсов на критических направлениях, включая создание научных школ, производственных коопераций и т. п., наша страна смогла добиться такого результата, что до сих пор плоды той работы определяют наше положение в этих отраслях.

В области электроники у нас уже есть успешные кейсы, но необходимо масштабировать их объемы, а также выстроить целостные технологические цепочки, замкнутый цикл. Нам нужно, чтобы у нас было всё от начала до конца, начиная от разработки и заканчивая выпуском конечных изделий, аппаратуры, созданием программного обеспечения, платформ, экосистем. Это включает множество направлений, которые должны работать в унисон.

Поэтому первым шагом должна стать организация взаимодействия - создание кооперационных цепочек. Это как раз то, что было разрушено со времен Советского союза. И этим мы будем сейчас активно заниматься.

Какие именно инструменты будут использоваться для построения кооперационных связей? Будут ли в эти связи включаться компании, у которых есть упомянутые вами кейсы?

Безусловно, мы будем опираться на профессионаловтех, кто уже вовлечен в создание электронных средств. Наша задача как регулятора - мотивировать их включаться в создаваемые кооперационные цепочки, заполнять пробелы в них. И основным инструментом для этой работы станут технологические консорциумы. Мы уже определили ряд направлений, по которым будут создаваться такие консорциумы - объединения компаний и организаций, заинтересованных в участии в развитии конкретной продуктовой линейки и готовых внести в него свой вклад. Со своей стороны, мы будем устанавливать определенные требования к этой продуктовой линейке. В то же время входящие в консорциумы организации смогут участвовать в выработке политики в соответствующем направлении, чтобы эти технологические цепочки работали наиболее эффективным образом.

Чтобы это можно было реализовать, мы приглашаем в консорциумы не только разработчиков и производителей микроэлектроники, электронных устройств и аппаратуры, но и сертификационные центры, испытательные лаборатории и т. п. Безусловно, это потребует активного участия фундаментальной науки, а также образовательных учреждений, ведь для выстраивания всей цепочки 
будут нужны подготовленные кадры, причем не только для разработки, но и для использования тех или иных решений

Например, если мы посмотрим на то, как последние 25 лет у нас готовились программисты, то увидим, что их обучали практически исключительно на процессорах архитектуры х86. Естественно, с их точки зрения, отечественные процессоры неприменимы - просто потому, что они с ними не знакомы, они даже не будут задаваться вопросом, хорошие или плохие эти решения. Поэтому потребуется определенная переподготовка и - даже больше - перестройка представлений, избавление от стереотипов.

Я хотел бы подчеркнуть, что здесь не идет речь о лоббировании конкретных бизнес-интересов тех или иных производителей. Это вопрос нашей идентичности, нашего места в цифровом мире будущего.

Помимо возможности непосредственного участия в развитии ключевых направлений, какая мотивация может быть у компании-разработчика для вступления в консорциум?

Мы планируем определенные меры, благодаря которым участники консорциумов получат возможность получить не только косвенные, но и прямые преимущества. Например, мы готовим предложение о снижении для разработчиков определенной аппаратуры ставок взносов в страховые фонды, по аналогии с разработчиками программного обеспечения, для которых эта ставка снижена с 30 до 14\%.

Вообще, в наших планах - серьезная поддержка интеллектуальной деятельности, поскольку, чтобы добиться прорыва в экономике знаний, куда мы активно движемся, нужно снизить налоговое давление на интеллектуальную деятельность, мотивировать людей заниматься научным творчеством.

Осенью прошлого года было объявлено о создании одного из новых отраслевых объединений - Ассоциации «Консорциум дизайн-центров и предприятий радиоэлектронной промышленности". Есть ли уже какие-либо результаты его работы? Будет ли департамент поддерживать эту структуру?

Консорциум дизайн-центров - это инструмент, который может дать результат в самой короткой перспективе. Сейчас в консорциуме идет активное формирование состава, органов управления. Его участники уже оказывают нам помощь, осуществляя экспертизу проектов нормативно-правовых актов, которые мы готовим, вносят множество ценных предложений. На этой площадке складываются подотраслевые технологические объединения, она помогает организации коммуникаций как между компаниями, так и между бизнесом и нашим департаментом.
Мы, конечно, будем это поддерживать, нам это необходимо. Объектом нашего внимания невозможно сделать каждое конкретное предприятие. Мы должны предлагать общесистемные отраслевые меры, а для того, чтобы эти меры были правильно сформулированы и полезны участникам рынка, нужны отраслевые ассоциации, такие как эта.

Если сравнивать, например, упомянутый вами космический проект и то, как развивалась электроника в мире, то в покорении космоса конкуренция была на уровне держав, а в электронике - скорее на уровне компаний. Нет ли опасности, что объединение усилий в рамках страны приведет к отсутствию внутренней конкуренции и, как следствие, к снижению мотивации к развитию?

Можно провести такую аналогию: как в космической аппаратуре обеспечение надежности немыслимо без резервирования, так и в промышленности и экономике очень рискованно опираться только на одно предприятие. Собственно, и в советской космической промышленности была конкуренция между несколькими КБ. Стоять на двух ногах всегда лучше, чем на одной

Но в условиях ограниченности ресурсов, которую мы сейчас имеем, "размазывать их тонким слоем» было бы неверно. Кроме того, практика показывает, что отечественные компании в нашей отрасли охотнее конкурируют между собой, чем с зарубежными производителями.

Поэтому в текущей ситуации более целесообразно сосредотачивать ресурсы на наиболее приоритетных направлениях, а не направлять их друг против друга. Технологические консорциумы должны послужить в том числе устранению такой необоснованной, неэффективной конкуренции.

В то же время этот подход не является запретительным в отношении конкуренции. Мы будем защищать всех отечественных производителей, продукция которых будет удовлетворять нашим требованиям.

Совсем недавно был подписан один из основополагающих документов - Постановление Правительства РФ от 10 июля 2019 года № 878 «О мерах стимулирования производства радиоэлектронной продукции на территории Российской Федерации при осуществлении закупок товаров, работ, услуг для обеспечения государственных и муниципальных нужд, о внесении изменений в Постановление Правительства Российской Федерации от 16 сентября 2016 года № 925 и признании утратившими силу некоторых актов Правительства Российской Федерации". В соответствии с этим документом будет создан единый реестр российской радиоэлектронной продукции по целому ряду кодов ОКПД 2, в который будет входить аппаратура, отвечающая заданным критериям российского происхождения, и она будет получать преференции при осуществлении государственных и муниципальных закупок. 
Также мы планируем программно-целевое планирование - подготовку дорожных карт для отечественных производителей по приоритетным направлениям. Однако, на мой взгляд, непосредственного госзаказа на разработку следует избегать. Вместо этого необходимо формировать рынки для российских производителей и тем самым поддерживать развитие их предпринимательской инициативы. Упомянутое постановление в том числе служит этой цели, и, как видите, выбор закупаемой продукции остается за заказчиком, а значит, развитие внутренней конкуренции при таком подходе не исключается.

Само собой, мы можем регулировать только закупки тех компаний, в которых государство имеет право голоса. Но мы хотим эту идеологию донести до всех участников российского рынка, чтобы и для коммерческих структур понятие "сделано в России" стало приоритетным. А этого невозможно добиться в директивном порядке, и определяющим в этом вопросе является качество продукции и сервиса, чему мы будем уделять особое внимание.

Что будет в основе критериев, исходя из которых продукция будет признаваться отечественной?

Одна из наших основных целей заключается в том, чтобы как можно бо́льшая доля добавленной стоимости оставалась внутри страны, поэтому здесь важно всё: от разработки и производства до программного обеспечения и сервиса. Очевидно, что на данном этапе по целому ряду продукции невозможно добиться того, чтобы вся технологическая цепочка была на территории России. Этот процесс растянут во времени. Но постепенно мы эти требования будем ужесточать, прежде всего настаивая на локализации с точки зрения электронных компонентов.

Еще один очень важный момент - интеллектуальная собственность и конструкторская документация должны принадлежать российскому юридическому лицу, более 50\% которого контролируется российскими резидентами

Следует также выделить вопрос программного обеспечения, поскольку, как я уже говорил, сегодня объектом продаж являются услуги, предоставляемые посредством программно-аппаратных платформ, и отделять ПО от аппаратной части было бы неверно. В упомянутом постановлении ясно прописано, что российской аппаратурой может считаться только та, которая использует российский софт, и мы хотим, чтобы подобная норма была прописана и для реестра отечественного ПО, администрированием которого занимается Минкомсвязи России. Если отечественное ПО работает на импортном процессоре, то должно адаптироваться и под российскую аппаратуру. С нашей точки зрения, это справедливо. Введение такой нормы могло бы качественно способствовать развитию и применению отечественных аппаратных решений.
Вы сказали, что по ряду продукции технологические цепочки не могут быть сейчас замкнуты внутри страны. Чего не хватает в первую очередь и как предполагается решать эту проблему? Насколько это возможно сделать в обозримые сроки?

Необходимо признать, что сейчас нам пока не хватает собственных компетенций по материалам, САПР, электронному машиностроению. Кроме того, изделие нужно не только спроектировать, но и изготовить. Поэтому необходимо построение промышленной инфраструктуры, и в этом мы сейчас видим вторую основную задачу, которой мы будем очень плотно заниматься.

Чтобы у нас была возможность производить современную микроэлектронику, нам нужны производства. Сегодняшние достижения в производстве микроэлектроники в Корее, Тайване, Китае напрямую связаны с государственной поддержкой. И мы должны пойти по этому пути. В создании производственной инфраструктуры государство будет оказывать поддержку, поскольку для частного инвестора сроки возврата этих инвестиций слишком велики. Эта работа уже ведется: проектируются и строятся новые производства, и совсем скоро наша страна будет иметь возможность производить микроэлектронные изделия по современным топологическим нормам

Но чтобы загрузить эти мощности, у нас должны быть разработки. Поэтому деятельность по созданию микроэлектронных изделий, приборов, аппаратуры мы должны разворачивать уже сейчас, параллельно с созданием производственной инфраструктуры. В этом вопросе уже необходимы частные инвестиции, а рольгосударства - создание благоприятных инвестиционных условий. Здесь эффективными механизмами являются субсидии, а также инструменты, гарантирующие рынок для российских разработок, такие как реестр, о котором я говорил ранее.

Одновременно с созданием инфраструктур разработки и производства необходимо придать импульс фундаментальным исследованиям, которые впоследствии обеспечат создание собственных материалов, оборудования, программных продуктов для проектирования, поскольку само по себе строительство фабрики и проектирование изделий на иностранных САПР не освобождает нас от зависимости. На этом пути есть возможность международной кооперации, потому что перед многими странами стоят те же проблемы. Но эта кооперация должна быть на понятных взаимовыгодных основах

Что касается сроков, в настоящее время технологии развиваются очень быстро, рынок претерпевает существенные изменения, и прецеденты развития за достаточно короткий период времени существуют. Например, какой была компания Huawei всего 10 лет назад? А сейчас это ведущая технологическая компания в мире. Так что, ничего невозможного в этом нет. 
Но если говорить о создании собственных материалов, технологий - это процесс в любом случае не быстрый. Можем ли мы догнать мировых технологических лидеров?

Действительно, за те годы, что мы не уделяли достаточного внимания электронной отрасли, в целом промышленности, фундаментальной науке, во многих направлениях мир ушел далеко вперед. Догонять, пытаясь получить у себя те технологии, которые уже 10-20 лет доступны нашим конкурентам, - это тупиковый путь. Необходимо делать ставку на новые прорывные технологии. Именно поэтому я и упомянул про инфраструктуру фундаментальных исследований.

В мире уже несколько лет говорится о приближении к пределам существующих подходов, в частности о том, что закон Мура перестает работать. Конечно, здесь нужно делать скидку на то, что закон Мура довольно-таки условен. Но это не отменяет того, что есть насущная потребность в принципиально новых решениях, новых материалах, принципах построения микроэлектронных изделий, новых архитектурах. Среди примеров направлений, в которых может случиться технологический прорыв, - квантовые вычисления, искусственный интеллект, радиофотоника, аддитивные технологии, новые полупроводниковые материалы и многое другое.

И здесь у нас есть шанс, учитывая интеллектуальный потенциал нашего общества и те заделы, которые у нас есть в различных областях. Наш главный козырь - человеческий капитал, и его надо ценить, взращивать, давать возможность для творчества, ставить нужные и интересные задачи. Необходимо искать новые подходы прежде всего в области фундаментальной науки, и уже на основе этих фундаментальных научных решений строить и развивать свою технологию. Весь мир сейчас ищет альтернативные пути дальнейшего развития, и это тот путь, на котором мы можем добиться успеха.

Каким образом можно заинтересовать творческого человека - инноватора, стартапера - вкладываться в такие рискованные направления, которые может быть станут основой для технологий будущего, а может быть и нет? Если речь идет о финансировании исследований, не очень ли это большой риск для государства?

Мне не очень нравится слово “стартапер". Я предпочел бы в этом контексте понятие "исследователь». Ведь стартапер - это человек, основной целью которого является получение финансирования, исследователь же "живет" идеями. Это совершенно разные люди с разными ценностями. А нам ведь нужны не красивые презентации, а результаты.

Мы сейчас рассматриваем такой вариант стимулирования реализации идей разработчикамиисследователями: создание платформы, на которой может зарегистрироваться разработчик, завести свой профиль, получить цифровую подпись, указать, в каких направлениях он специалист. Система, если мы говорим про микроэлектронику, предоставляет ему набор инструментов для проектирования, и он решает задачу, после чего результатами могут воспользоваться заказчики, зарегистрированные в системе, а разработчик гарантированно получает вознаграждение при каждом использовании его разработки. Система и сама может предложить задачу разработчику от потенциальных заказчиков в соответствии с его компетенциями. Более того, может быть реализован и сервис обучения тем или иным инструментам с присвоением определенной оценки разработчика в системе. Конечно, реализация этой модели требует проработки, там имеются определенные "подводные камни». Но такая модель привлекательна тем, что исследователь не вкладывает ничего, кроме своих знаний и времени, при этом получая гарантию дохода в случае востребованности своей идеи или разработки.

Вы рассказали о некоторых планируемых мерах стимулирования и поддержки, направленных на развитие отечественной микроэлектроники и электроники в целом. Чем компаниям отрасли можно или даже нужно воспользоваться прямо сейчас?

Я хотел бы обратить внимание на Постановление Правительства РФ от 17 февраля 2016 года № 109 «Об утверждении Правил предоставления из федерального бюджета субсидий российским организациям на финансовое обеспечение части затрат на создание научно-технического задела по разработке базовых технологий производства приоритетных электронных компонентов и радиоэлектронной аппаратуры». Согласно этому документу нашим заявителям за счет государства может быть возмещено до 50\% затрат на НИОКР по следующим направлениям: вычислительная техника, телекоммуникационное оборудование, специальное технологическое оборудование и системы интеллектуального управления. Поэтому призываю всех внимательно ознакомиться с этим постановлением, проанализировать свои перспективные разработки, заделы, обратиться к нам за поддержкой и довести свои наработки до востребованного результата.

А в целом, чем больше обращений к нам будет, чем больше компаний подключатся к деятельности консорциумов и отраслевых ассоциаций, чем больше идей и вопросов будет доноситься до нас, тем проще будет отстаивать отраслевые интересы, доносить позицию до руководства страны, быстрее и эффективнее достигать поставленных целей. Только вместе, только сообща можно двигаться вперед!

Спасибо за интересный рассказ.

С В. В. Шпаком беседовап Ю. С. Ковалевский 

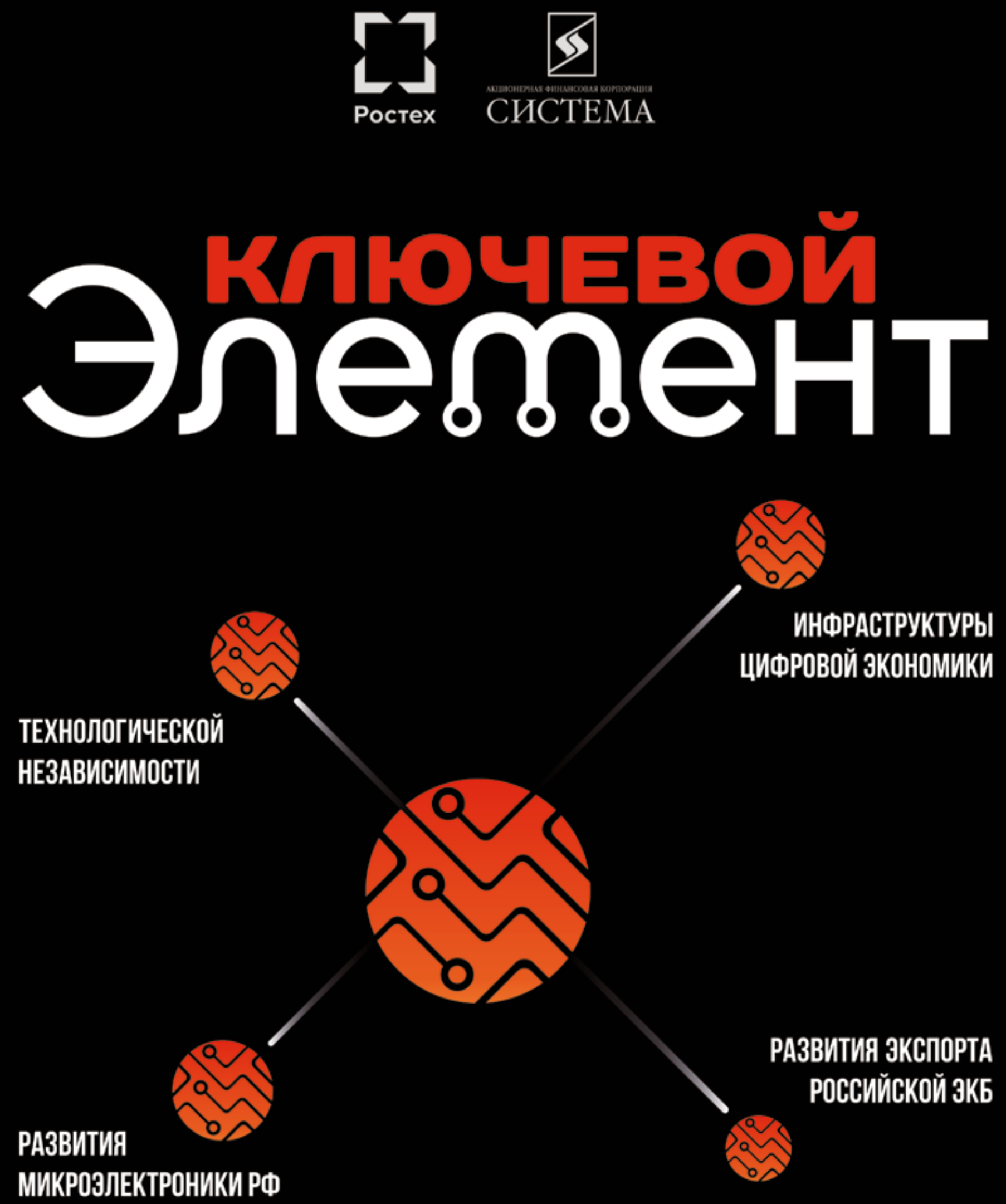

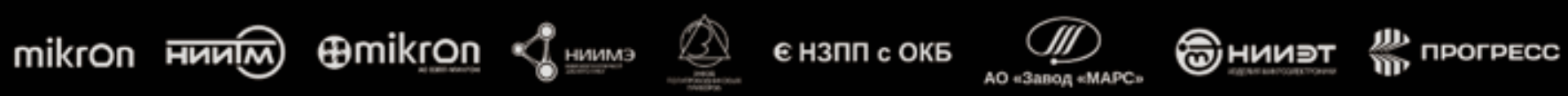




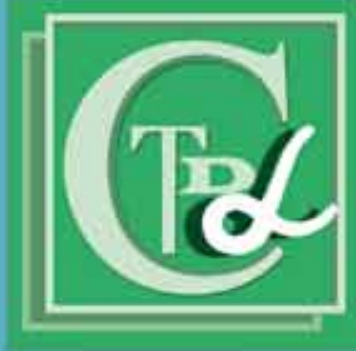

\section{УВАЖАЕМЫIE KONЕГИ!}

Paна сообщить вам o pacширени возможностей испытательной лаборатории Групшы компаний ТД кАльфаКомпдект" ОКБ аа счет приобретения новой установки сканирующей акустической микроскопи, позволяющей вћиявлить контрафактние муектронните компоненты по признакам, недостушным для визуального и рентгеновского кончролі.

В современшых уеловнях при применени алектронной комшонентной базы (ЭКБ) как викогда остро встает вопрос зашеты or контрафакта. Ora ироблема нвляется общемировой. B чістностн, NASA бынh випущена директина, требуюшаи ироверки на контрафакт всей ЭКБ, применяемой в аapokocмитеской ammapatype.

В нашеї стране даноому вопросу также уделяетси очень большое внимание, и, согласво действуюшим требованиям, әлектронные компоненты иностранного пронаводетва, предназначеншке для прнменевия в определснитх

\section{В СОВРЕМЕННЫХ УСАОВИЯХ ПРИ ПРИМЕНЕНИИ ЭКБ КАК НИКОГАА ОСТРО ВСТАЕТ ВОПРОС ЗАЩИТЫ OT KOHTPAФAKTA}

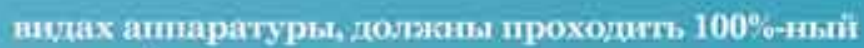
входной контроль в том чиеле на предмет выявления контрафакта.

Ряд контрафактних нзделий может быть мкивлен по внешнему виду, а также с помошію измерения их конструктинно-технологических mараметров, таких как масса и габаритh. Другуо контрафактную ироцукшио мояно определить, исследуя ниутреннию структуру комповента, нашример размеры крнстална и разварку выводов, с помощью ренттена. Однако әти виды контроля не всегда позволяют установиты, лвляется ли изделие контрафактным. В частности, одним из распространенных способов вьщать несоответствуюший компонент за тот, который требуется заказчику, является его перемғаркировка, которая может бить витониена достаточно качественно, не позволия вьлтить подмену путем обычного визуального осмотра даже с помощью увеличения. В этой сптуаши рентен также оказывается бессилен.

Прімерами пеползования перемаркировки могут служсть изменение даты вытуска, нанесенной на компонент с уже истекшим сроком годности, нщи замена всего одной буквы в обозначении микросхеми, которая "иревращает" компонент коммерческого назначения в компонент провпишенной, военной или даже азрокосмической категории, на соответствие которой ота микроскема, само собой, не испьтывалась и, вероятне всего, не будет способна вьцержать столь жесткие условия әкспиуатацші. 
Исшытательная лаборатория Грушшы компаний ТД «Альфа-Комплект" ЭКБ уле несколько лет имеет в своем распоряжении рентгеновскую установку, позволяющую, помимо прочего, выявлять некоторые виды контрафактиых электронных компонентов.

Сейчас возможности лаборатории расширились, благодаря приобретению сканирующего акуетического микроскопа VUE 250-P иронзводства комшании OKOS. Технология пифровой акустической микроскопии позволяет выяилять контрафактные ияделия по признакам, которые не могут быть определены с помошыо ренттена. Установка VUE 250 - $\mathrm{P}$ обеспечивает получение послойных изображений как пластиковых, так и металлических кориусов, отражающих неоднородности структур, в частности следы оритинальной маркировки даже при тщательном ее удалении. Даже если при перемаркировке новые надинси нанесены строго поверх старых, на контрафакт могут указывать косвенные иризнаки, такие как нашыы-

\section{ВОЗМОЖНОСТИ НАШЕЙ \\ ААБОРАТОРИИ РАСШИРИАИСЬ \\ БААГОААРЯ ПРИОБРЕТЕНИЮ \\ СКАНИРУЮЩЕГО АКУСТИЧЕСКОГО МИКРОСКОПА VUE 250-P \\ ПРОИЗВОАСТВА КОМПАНИИ ОКОS}

вы на клиоах, боковнх стенках кориуса и т. п. Область сканирования микроскопа VUE 250-P соответствует размерам стандартного JEDECподдона $(322,6 \times 136$ мм), что позволяет выполнять контроль без извлечения компонентов из подцона и сократит. временные затраты на загруаку и выгрузку, а разрешение установки, составляющее \pm 1 мкм, обеспечивает выполнение всех практических задау, связанных с выявлением контрафакта методом сканирующей акустической мптроскошии.

Результаты сканирования выводятея в реальном времени на два монитора, на одном из которых показывается текущий продесс ска-

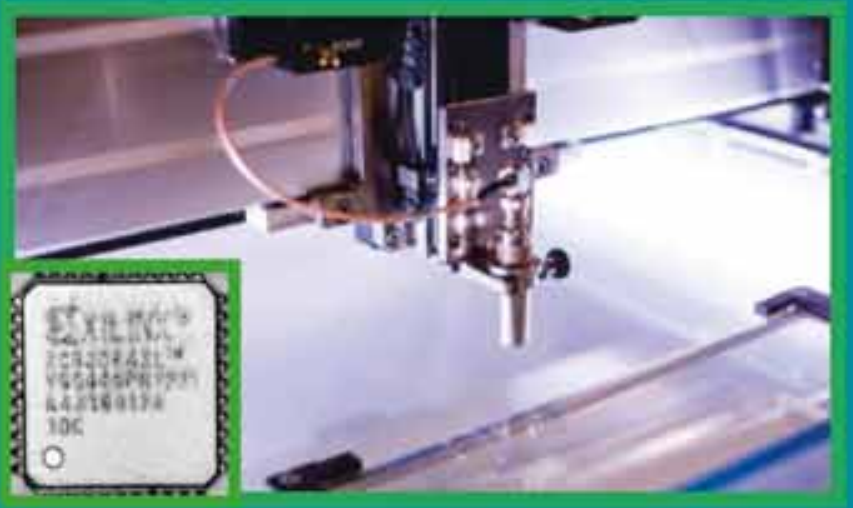

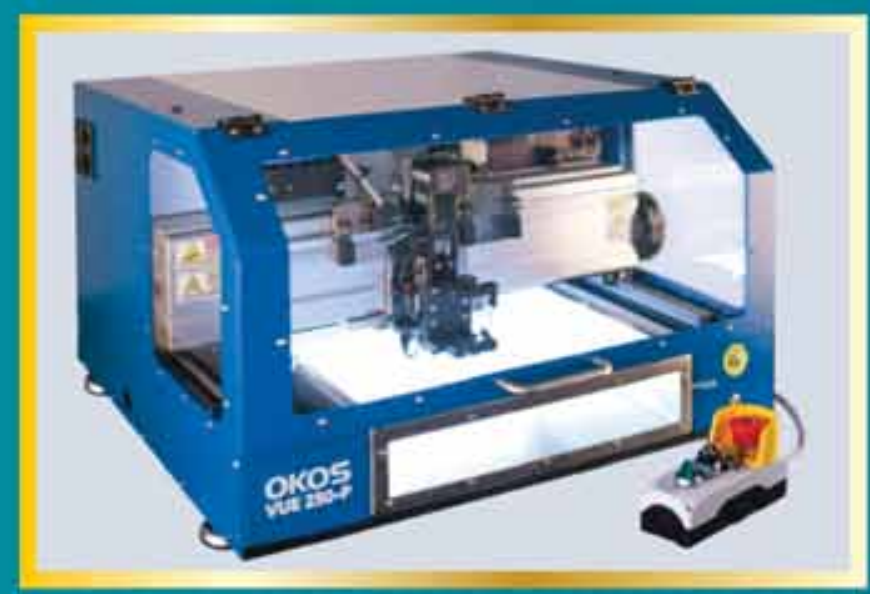

нирования, а на другом - формируется изобраякение послойной структуры. Полученные изображения имеют шифровой формат, что позволяет использовать их в качестве иллюстраций к отчетам. Особенностыю установки VUE 250-P является то, что, помимо получения послойных изображений структур, она способна определнть наличие влаги в кориусе

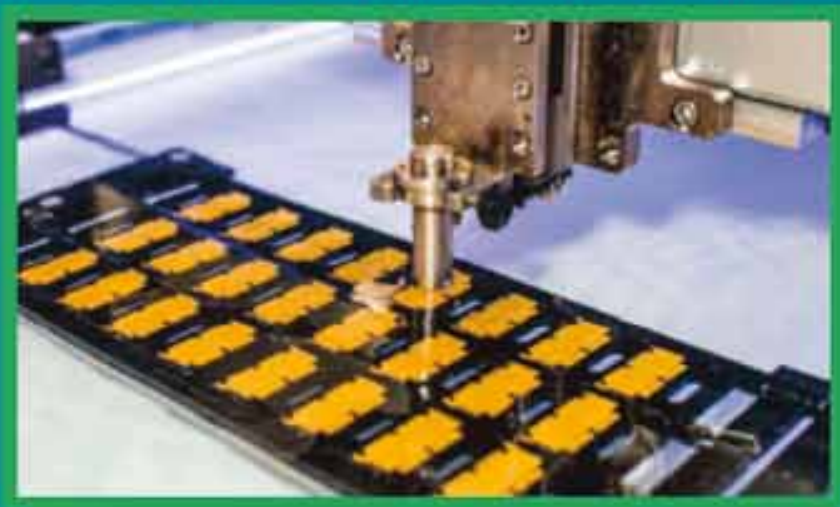

компонента неразрушающим методом, технически позволяюшим заменить разрушающий контроль методом прокальвания корпуса. Выявление контрафактной ОКБ ИН с помощью сканирующего акустического микроскопа VU2 250-P будет выполияться в нашей лаборатории в соответствии с действуюшими нормативными требованиями и регламентами. Мы нланируем начало оказания данных услуг c использованием новой установки в конце августа 2019 года.

Надеемся, что новые возможности нашей лаборатории послужат успешному выполнению вапих задач, натравленных на создание современных конкурентоспособных изделий отечественной алектроники и достикение технологтческото превосходства нашей страны!

ГенераАьный Аиректор Группы КОмпаний ТА «Аиьфа-КомпиеКт) ЭКБ Амексанара Ивановна РОман 